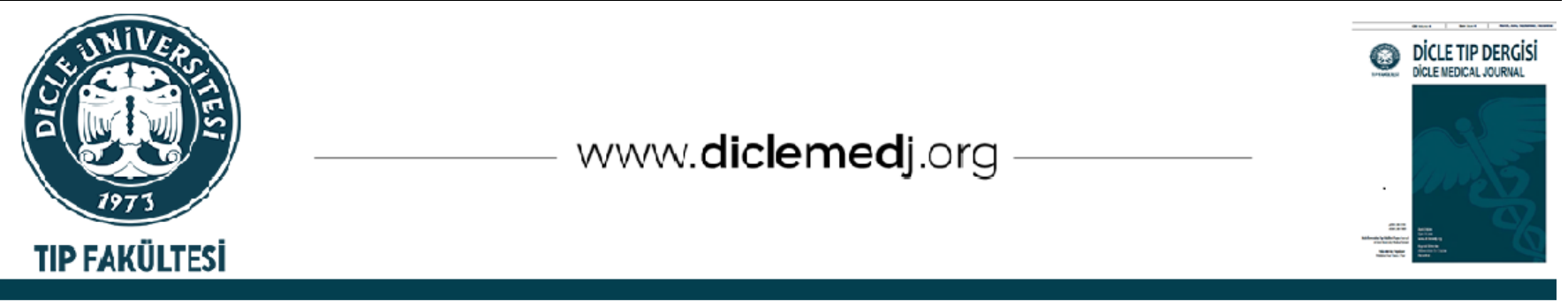

Özgün Araştırma / Original Article

\title{
Turner Sendromlu Olguların Değerlendirilmesi
}

\author{
Edip Unal ${ }^{\mathrm{D}} \mathbf{1}$, Yusuf Kenan Haspolat ${ }^{\mathrm{D}}{ }_{1}$ \\ 1 Dicle Üniversitesi Tıp Fakültesi Çocuk Endokrinolojisi Bilim Dalı, Diyarbakır, Türkiye \\ Geliș: 31.10.2020; Revizyon: 06.12.2020; Kabul Tarihi: 07.12.2020
}

$\ddot{0} \mathbf{z}$

Amaç: Turner sendromu X kromozomlarından birinin kaybı veya yapısal bozukluğu sonucu gelişen ve 2500 doğumda bir görülen genetik bir hastalıktır. Turner sendromu birçok sistemi etkilemektedir. Bu çalışmada Turner sendromlu olgularımızın klinik özellikleri ve eşlik eden anormalliklerin sıklığının değerlendirilmesi amaçlanmıştır.

Yöntemler: Çocuk Endokrinolojisi polikliniğinde Ocak 2013-Ocak 2020 tarihleri arasında Turner sendromu tanısı alan hastaların dosyaları retrospektif olarak incelendi. Dosya kayıtlarından hastaların antropometrik ölçümleri, karyotip analizi, başvuru yaş ve şikayetleri, eşlik eden kardiyak, renal ve işitme problemleri ve otoimmün hastalık olup olmadığı kaydedildi.

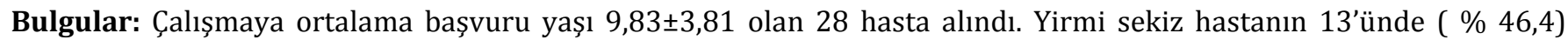
karyotip analizi 45, X0 saptandı. Başvuru esnasında hastaların ortalama boy standart deviasyon skoru: $-3,61 \pm 1,17$ idi. Yirmi sekiz olgunun 7'sinde (\% 25) kardiyak patoloji, 3'ünde (\% 10,7) atnalı böbrek anomalisi, 3'ünde $(\%$ 10,7) Hashimoto tiroiditi hastalığı ve 2'sinde $(\% 7,1)$ Alanin transaminaz yüksekliği saptandı. İşitmesi değerlendirilen 19 hastanın 8'inde (\% 42,1) iletim tipi işitme kaybı mevcuttu. Tanı esnasında 27 hastanın pubertesi Tanner evre 1 iken, 1 olguda pubertenin spontan başladığı ve menarş olduğu tespit edildi. Tüm hastalar boy kısalığı ile başvurmuştu.

Sonuç: Turner sendromunun en sık görülen iki bulgusu boy kısalığı ve gecikmiş pubertedir. Bunun dışında kalp ve böbrek hastalıkları, gastrointestinal sistem ve işitme problemleri, otoimmün hastalık sıklığında artış gibi başka sistemleri de etkilemektedir. Daha iyi bir final boya ulaşmak ve eşlik eden patolojilerle ilgili komplikasyonları önlemek için erken tanı oldukça önemlidir. Bu çalışma, çocuklarda boy kısalığı ve hipergonadotropik hipogonadizm gibi kardinal bulguların olmamasının, Turner sendromu tanısını ekarte etmeyeceğini göstermiştir.

Anahtar kelimeler: Turner sendromu, boy kısalığı, gonadal disgenezi

DOI: 10.5798/dicletip.850533

Correspondence / Yazışma Adresi: Edip Unal, Dicle Üniversitesi Tıp Fakültesi Çocuk Endokrinolojisi Bilim Dalı, Diyarbakır, Türkiye; email:edip76@yahoo.com 


\section{Evaluation Of Cases With Turner Syndrome}

\section{Abstract}

Objective: Turner syndrome is a genetic disease that develops as a result of the loss or structural defect of one of the $\mathrm{X}$ chromosomes and is seen in every 2500 births. Turner syndrome affects many systems. In this study, it was aimed to evaluate the clinical characteristics of our TS cases and the frequency of accompanying abnormalities.

Methods: The files of patients diagnosed with TS between January 2013 and January 2020 in The Pediatric Endocrinology outpatient clinic were retrospectively analyzed. Anthropometric measurements, karyotype analysis, admission age, complaints, accompanying cardiac, renal problems, hearing problems, and autoimmune disease were recorded from the file records.

Results: Twenty-eight patients with an average age of $9,83 \pm 3,81$ were included in the study. Karyotype analysis 45 , X0 was detected in $13(46.4 \%)$ of twenty-eight patients. The mean height SDS of the patients at admission was $-3,61 \pm 1,17$. In twenty-eight cases, cardiac pathology was detected in 8 (28.6\%), Horseshoe kidney anomaly in $3(10.7 \%)$, Hashimoto disease in $3(10.7 \%)$, and alanine-transaminase elevation in 2 (7.1\%). Eight (42.1\%) of 19 patients whose hearing was evaluated had conductive hearing loss. The puberty of 27 patients at diagnosis was Tanner stage 1, in one case, it was found that puberty started spontaneously and had menarche. All patients presented with short stature.

Conclusion: The two most signs of Turner syndrome are short stature and delayed puberty. Apart from this, it affects many systems such as heart and kidney diseases, gastrointestinal and hearing problems, and an increase in the frequency of autoimmune diseases. Early diagnosis is very important in order to achieve a better final height and prevent complications related to concomitant pathologies. This study showed that the absence of cardinal findings such as short stature and hypergonadotropic hypogonadism in children would not rule out the diagnosis of Turner syndrome.

Keywords: Turner syndrome, short stature, gonadal dysgenesis.

\section{GÍRIŞ}

Turner sendromu (TS) kiz cinsiyette $\mathrm{X}$ kromozomlarından birinin tamamen yokluğu veya $\mathrm{X}$ kromozomunun birinde yapisal defekt veya kısmi eksiklik sonucu ortaya çıkan, yaklaşık 2500 canlı doğumda bir görülen bir hastalıktır. Kız cinsiyette en sık görülen genetik bozukluklardandır ${ }^{1-3}$. Turner sendromu ilk kez 1938 yılında boy kısalığı, yele boyun, ergenlik gelişiminde gecikme ve kollarda kubitus valgus deformitesi olan kı çocuklarında tanımlanmıştır ${ }^{4}$. Ancak, Otto Ulrich birkaç yıl önce benzer fenotipe sahip sekiz yaşındaki bir kız çocuğunu bildirmişti ${ }^{5}$. Turner sendromunda en sık görülen bulgular boy kısalığı ve gonadal yetersizlik iken, konjenital ve edinsel kardiyovasküler sistem hastalıkları, böbrek anomalileri, iskelet anomalileri, ișitme sorunları ve artmış otoimmün hastalık riski gibi birçok sistemi de etkilemektedir6,7. Birçok sistemi etkileyen TS ve ilişkili anormalliklerin erken tanınması, hastaların daha iyi bir yaşam kalitesine sahip olmasına olanak sağlayacaktır. $\mathrm{Bu}$ çalışmada TS'li olgularımızın klinik özellikleri ve eşlik eden anormalliklerin sıklığının değerlendirilmesi amaçlanmıştır.

\section{YÖNTEMLER}

Çalışmaya Ocak 2013 ile Ocak 2020 tarihleri arasında hastanemiz Çocuk Endokrinoloji polikliniğinde TS tanısı konulan 28 hasta alındı. Hasta dosya kayıtlarından çalışmaya dahil edilen tüm hastaların TS tanısı periferik kandaki lenfositlerden yapılan karyotip analizi ile konulmuştu. Periferik kan lenfositlerinden makro-kültür tekniğinin kullanıldığı ve her hasta için en az 20 metafaz plağı elde edildiği öğrenildi. Dosya kayıtlarından hastaların karyotip analizi dışında; başvuru yaş ve şikayetleri, eşlik eden kardiyak ve renal patolojileri ve otoimmün hastalık (Çölyak ve Hashimoto) olup olmadığ kaydedildi. Tanı esnasında tüm hastaların ağırlık (kg), boy $(\mathrm{cm})$, ağırlık ve boy standart deviasyon skoru (SDS) 
hesaplandı. Çalışmaya dahil edilen tüm hastaların antropometrik ölçümleri Türk çocuklarının normal değerleri ile kıyaslandı ${ }^{8}$. Ağırlık 0,1 kg hassasiyetle ölçüm yapan SECA (GMBH \& CO KG Hamburg, Germany) tartısıyla bakıldı. Boy uzunluğu 0,1 cm duyarlılığa sahip Harpenden stadiometresi (Holtain Limited, Crymych, Dyfed, U.K) ile ölçüldü. Hastaların pubertelerini değerlendirmek için Tanner evrelemesi kullanıldı ${ }^{9}$. Olguların kardiyak bulguları çocuk kardiyoloji uzmanı tarafından yapılan transtorasik ekokardiyografi raporuna göre, böbrek ve toplayıcı sistem sorunları ise radyoloji uzmanı tarafından yapılan üriner ultrasonografi raporuna göre belirlendi. Hasta dosya kayıtlarından işitme değerlendirilmesinin, Hashimoto tiroiditi için tiroid oto-antikorlarının ( anti-tiroidperoksidaz ve anti-tiroglobülin), Çölyak hastalığı için doku transglutaminaz-IgA düzeylerinin bakılıp bakılmadığı kaydedildi.

Çalışma Dicle Üniversitesi Tıp Fakültesi Girişimsel Olmayan Klinik Araştırmalar Etik Kurulu onayı alındıktan sonra yapılmıştır (2020 / 323).

\section{İstatistiksel Analiz}

Çalışmadaki verilerin istatistiksel değerlendirmesinde SPSS 20.0 istatistik paket programı kullanıldı. Ölçümsel değişkenler normal dağılım gösterdiği için ortalama \pm standart sapma (SD) ile, kategorik değişkenler ise sayı ve yüzde (\%) ile belirtildi.

\section{BULGULAR}

Çalışmaya ortalama tanı yaşı $9,83 \pm 3,81$ olan 28 hasta alındı. Yapılan sitogenetik analiz sonuçlarına göre çalışmaya dahil edilen 28 hastanın 13'ünde ( $\% 46,4) 45$, X0, altı olguda $(\% 21,4) \quad 46, \mathrm{X}, \mathrm{i}(\mathrm{X})(\mathrm{q} 10)$, üç olguda $(\% 10,7)$ $45, \mathrm{X} 0$ / 46, XX, üç olguda $(\% 10,7) 45, \mathrm{X} 0$ / $46, \mathrm{X}, \mathrm{i}(\mathrm{X})(\mathrm{q} 10)$, iki olguda $(\% 7,2) 45, \mathrm{X0} /$ 46,X,del(X), bir olguda $(\% 3,6) 45$, X0 / 47, XXX kromozomal kompozisyon saptandı (Tablo 1).
Tablo I: Turner sendromlu olguların karyotip analizleri

\begin{tabular}{|l|l|}
\hline Karyotip Analizi & Sayı (\%) \\
\hline 45, X0 & $13(46,4)$ \\
\hline $46, X, i(X)(q 10)$, & $6(21,4)$ \\
\hline $45, X 0 / 46, X X$ & $3(10,7)$ \\
\hline $45, X 0 / 46, X, i(X)(q 10)$ & $3(10,7)$ \\
\hline $45, X 0 / 46, X, d e l(X)$ & $2(7,2)$ \\
\hline $45, X 0 / 47, X X X$ & $1(3,6)$ \\
\hline
\end{tabular}

Başvuru esnasında hastaların ortalama ağırlık SDS değeri: $-2,13 \pm 1,75$, boy SDS değeri: $-3,61 \pm$ 1,17 olarak saptandı. Çalışmaya alınan 28 hastanın 27'sinde $(\% 96,4)$ boy kısalığ mevcut iken, bir olguda $(\% 3,6)$ boy ölçümü normal idi. Yirmi sekiz olgunun yedisinde (\%25) kardiyak patoloji saptanırken, üç olguda $(\% 10,7)$ atnalı böbrek anomalisi, üç olguda $(\% 10,7)$ Hashimoto hastalığı ve iki olguda $(\% 7,1)$ Alanin transaminaz yüksekliği mevcut idi. Kardiyak patolojisi saptanan yedi hastanın ikisinde Aort koarktasyonu, ikisinde Bikuspit aort kapağı saptanırken, birer olguda da Aort yetmezliği, sekundum atriyal septal defekt, sol ventrikül aberran band saptand. Dosya kayıtlarından işitmesi değerlendirilen 19 hastanın 8'sinde $(\% 42,1)$ belli oranlarda iletim tipi işitme kaybı olduğu tespit edildi. Tanı esnasında 27 hastanın pubertesi Tanner evre 1 iken, bir olguda pubertenin spontan başladığı ve menarş olduğu tespit edildi. Hastaların başvuru özellikleri ve diğer sistem bulguları Tablo 2'de özetlenmiştir.

Tablo II: Hastaların başvuru özellikleri ve eşlik eden diğer sistem bulguları

\begin{tabular}{|l|l|}
\hline Ortalama tanı yaşı (ortalama \pm SD) & $9,83 \pm 3,81$ \\
\hline Ağırlık SDS & $-2,13 \pm 1,75$ \\
\hline Boy SDS & $-3,61 \pm 1,17$ \\
\hline Kalp bulguları (\%) & 25 \\
\hline Böbrek anomalisi (\%) & 10,7 \\
\hline İletim tipi işitme kaybı (\%) & 42,1 \\
\hline Hashimoto hastalığı (\%) & 10,7 \\
\hline ALT yüksekliği (\%) & 7,1 \\
\hline
\end{tabular}

SD: Standart deviasyon, SDS: Standart deviasyon skoru, ALT: Alanin transaminaz 


\section{TARTIŞMA}

Turner sendromu, 100.000 kadında 25-50 kişiyi etkiler ve yaşamın tüm evrelerinde birden çok organı tutabilir, bu da multidisipliner bakım yaklaşımını gerektirmektedir. Turner sendromu tanısı kız olgularda, iki X kromozomdan birinin tamamen veya kısmen eksik olması veya kromozom yapısının anormal olması ile birlikte klinik bulguların da gözlenmesi esasına dayanmaktadır7. Daha önce yapılan çalışmalara göre Turner sendromundaki kromozom anormalliklerinin sıklığı ve tipi şu şekildedir: Olguların \% 4050'sinde monozomi X ( 45, X0), \% 15-20'sinde mozaisizim (45,X / 46,XX), \% 10-12'sinde mikst gonadal disgenezi $(45, X$ / 46,XY), \% 10'unda izokromozomlar (46,X i(Xq); 46,X,idic(Xp)), \% 3'ünde üçlü $X$ kromozomlu mozaisizim (45,X/47,XXX; 45,X/46,XX/47,XXX), geri kalan olgularda ise Xp22.3 delesyonu ve halka kromozomlar $\quad(46, X X, \quad \operatorname{del}(\mathrm{p} 22.3)$; 46,X,r(X)/46,XX) oluşturmaktadır. Karyotip analizi 45,X / 46,XY olup erkek fenotipli olgular TS dışında tutulmalıdır7. Bizim çalışmamızdaki olguların karyotipleri incelendiğinde olguların $\%$ 46,4'ünde 45, X0 saptandl ve bu bulgu literatür ile uyumluydu.

Turner sendromunun en sık görülen bulgusu boy kısalığıdır. Turner sendromlu kız çocukları sıklıkla hafif büyüme geriliği ile doğarlar. Bu olgularda lineer büyümenin hem infant hem de çocukluk döneminde yavaş olduğu gösterilmiştir. Özellikle puberte döneminde pubertal boy sıçramasının olmaması nedeniyle boy kısalığı daha belirgin hale gelmektedir. Ancak belirgin boy kısalığı bulgusuna rağmen TS'li kız çocuklarının çoğuna 8-10 yaşından önce tanı konulamamaktadır ${ }^{10}$. Ülkemizde TS ile ilgili çok merkezli yapılan bir çalışmada ortalama tanı yaşının $10,1 \pm 4,4$ yıl ve ortalama boy SDS'lerinin $-3,1 \quad \pm \quad 1,7 \quad$ olduğu gösterilmiştir ${ }^{11}$. Çalışmamızda olgularımızın TS tanısı alma yaşının literatür verileri ile uyumlu olduğu tespit edilmiştir ${ }^{10,11}$. Ayrıca olgularımızın boy SDS değerlerinin ülkemizde yapılan çok merkezli çalışmanın verileriyle uyumlu olduğu gösterilmiștir ${ }^{11}$. Çalışmamıza dahil edilen 28 olgunun 27'sinde $(\% 96,4)$ boy SDS değerleri -2'nın altında iken, bir olguda $(\% 3,6)$ boy SDS değeri $-1,62$ olarak saptand. Boyu sinırda normal olan olgumuzun karyotip incelemesinde mozaisizim mevcuttu. Hastaların sağlık kuruluşlarına geç başvurması veya herhangi bir şekilde tanının gecikmesi bu olguların büyüme hormon tedavisinden daha az fayda görmesine neden olacaktır. Turner sendromlu olgularin tedavisiz birakılması halinde erişkin boylarının normal kadın popülasyona göre yaklașık $20 \mathrm{~cm}$ kadar kısa kaldığı gösterilmiştir ${ }^{12}$. Ülkemizde çok merkezli olarak yapılan bir çalışmada tedavi edilmemiş TS vakalarının erişkin boyları 141,6 cm olarak bulunmuştur ${ }^{13}$. Aynı çalışmada tedavi verilmeyen TS vakalarının ortalama normal kadın boyuna göre 18,4 cm kadar kısa kaldıkları gösterilmiştir ${ }^{13}$. Turner sendromunda boy kısalığının; intrauterin büyüme geriliği, $\mathrm{X}$ kromozomu üzerinde bulunan SHOX gen mutasyonu, primer ovaryan yetmezlik nedeniyle pubertal gelişimin olmaması, büyüme hormon salınımının bozulması, nöro-sekretuar disfonksiyon, büyüme hormonu-IGF aksındaki bozukluklar ve IGF'eye direnç gibi birçok faktöre bağlı olduğu düşünülmektedir ${ }^{14,15}$.

Primer gonadal yetersizlik, TS'nın en yaygın özelliklerinden biridir. Etkilenen kadınların çoğunda meme gelişimi olmayıp primer amenore vardır. Turner sendromlu kadınların yaklaşık \%15-30'unda ise pubertenin spontan olarak başladığı gösterilmiştir. Kadınların \%6'sının normal pubertal gelişime ve düzenli menstrüasyona sahip olduğu rapor edilmiştir. Spontan puberte veya düzenli menstrüasyon gören olguların daha çok mozaisizimli olgular olduğu bildirilmiştir7,12,16-18. Turner sendromlu ve 12 yaşın üzerindeki 522 hastanın retrospektif olarak incelendiği bir çalışmada 84 olgunun (\%16) ortalama 13,2 yaşında spontan 
menarş olduğu raporlanmıştır. Ayrıca bu 84 olgunun 30'unda menarştan dokuz yl geçmesine rağmen hala düzenli adet gördükleri ve üç olguda spontan gebelik geliştiği bildirilmiştir ${ }^{18}$. Çalıșmamızda da pubertesi spontan olarak başlayan ve düzenli adet gören, ancak boy kısalığı olan bir olguya TS tanısı konulmuştur. On üç yaşında menarş olan hastamızın karyotip analizi 45, X0 idi. Bu nedenle her ne kadar TS'li kadınlarda normal menarş yaygın olmasa da, açıklanamayan boy kısalığı olan kız çocuklarında pubertesi normal ve düzenli adet görseler bile TS olasılığı göz önünde bulundurulmalıdır.

Turner sendromlu bireylerde konjenital ve edinsel kardiyovasküler hastalık nedeniyle artmış morbidite ve mortalite riskine sahiptirler ${ }^{7}$. Konjenital kalp hastalıkları TS'li olguların yaklaşık \%50'sinde görülmektedir. En sık görülen patolojiler biküspit aort kapağı ve aort koarktasyonu iken, nadir görülen fakat ölümcül diseksiyona veya torasik aort rüptürüne yol açabilen aortopati gibi patolojiler de görülebilir7,12,19. Ayrıca ventriküler septal defekt, atriyal septal defekt, sistemik venöz anomaliler, pulmoner venöz anomaliler ve koroner arter anomalilerinin de görüldüğü rapor edilmiştir ${ }^{12,19}$. Kardiyovasküler anomalisi olan olguların daha çok 45, X0 karyotipli olgular olduğu tespit edilmiştir ${ }^{7,20}$. Çalışmamızdaki 28 olgunun 7'sinde (\% 25) konjenital kalp hastalığı saptandı. İki olguda aort koarktasyonu, iki olguda bikuspit aort kapağı, birer olguda da sekundum ASD, sol ventrikül aberran band ve aort yetmezliği tespit edildi. Kardiyak patoloji saptanan 7 olgunun 4'ünde karyotip analizi 45, XO idi ve bu durum literatür bulguları ile uyumlu olarak değerlendirildi. Turner sendromlu olgularda hipertansiyon sıklığı normal popülasyona göre daha yüksektir. Yaşları 5 ile 22 arasında değișen ve 62 olgunun alındığı bir çalışmada olguların \%30'unda hafif hipertansiyon olduğu, \%50'sinde ise anormal diürnal kan basıncı profiline (24 saatlik ambulatuvar kan basıncı ölçümü ile) sahip oldukları gösterilmiştir ${ }^{21}$. Çalışmamızda hasta dosyalarından tansiyon değerlerine ulaşılamadığından hipertansiyon sıklığı tespit edilememiştir.

Turner sendromlu hastaların yaklaşık \%3040'ında böbrek veya üriner sistemin konjenital malformasyonları mevcuttur. Daha çok toplayıcı sistem anomalileri (\%20) ve at nalı böbrek gibi pozisyon anomalileri (\%10) görülmektedir. Pozisyonel anomaliler karyotipi 45, X0 olan hastalarda daha sık görülmektedir. Bazı çalışmalarda TS'li olguların \%5'inde böbrek malrotasyonu ve diğer pozisyon anormallikleri gözlenmiștir ${ }^{22}$. Üreteropelvik bileşke ile ilgili anomaliler, hidronefroz ve piyelonefrit riski oluşturabilir ${ }^{12}$. Böbrek anomalilerini tanımlamak için, TS tanısı esnasinda böbrek ve üriner sistem ultrasonografisi çekilmesi önerilmektedir ${ }^{7,12}$. Çalışmamızdaki 28 olgunun 3'ünde (\% 10,7) at nalı böbrek anomalisi vardı ve her üç olgumuzun da karyotipi literatür ile uyumlu olarak 45, X0 saptand. Ancak renal anomali sıklığı daha önceki çalışmalara kıyasla daha düşüktü.

Turner sendromunda Hashimoto tiroiditi, Çölyak hastalığı ve İnflamatuvar barsak hastalığı gibi otoimmün hastalıklar riskinde artış mevcuttur ${ }^{23-25}$. Ülkemizde 842 hastayı içeren çok merkezli bir çalışmada Hashimoto sıklığının \%10,4, Çölyak sıklığının ise \%2,6 olduğu tespit edilmiştir ${ }^{26}$. Çalışmamızda Hashimoto tiroiditi sıklığı \%10,7 saptanırken, hiçbir olgumuzda ek otoimmün hastalık saptanmadı. Çalışmamızda Hashimoto sıklığı literatürle uyumlu iken, Çölyak başta olmak üzere ek otoimmün hastalıkların saptanmaması hasta sayısının az olması ile ilişkilendirilmiştir.

Turner sendromlu hastalarda işitme problemleri oldukça sık görülmektedir. Östaki tüpleri ve kafa tabanındaki anormallikler nedeniyle tekrarlayan orta kulak enfeksiyonları ve orta kulakta efüzyonlar görülebilir. $\mathrm{Bu}$ 
durum iletim tipi işitme problemlerine yol açar ${ }^{27}$. Progresif sensörinöral işitme kaybı, erişkin dönemdeki hastaların \%50'sinden fazlasında görülmektedir. İşitme kaybının, kokleanın alt orta sarmalının dış tüylü hücrelerindeki bir kusurla ilişkili olduğu düşünülmektedir ${ }^{28}$. Turner sendromu aynı zamanda orta kulaktaki keratinize skuamöz epitel hücrelerinin anormal büyümesi (kolesteatom) için artmış risk ile ilişkilidir. Bu da progresif bir şekilde büyüyerek iletim tipi işitme kaybına ve zamanında teşhis edilip tedavi edilmezse orta kulakta harabiyete neden olabilir ${ }^{29}$. Çalışmamız retrospektif olarak yapıldığı için tüm olguların işitme değerlendirilmesi için kulak burun boğaz hekimine yönlendirilmediği fark edilmiştir. İşitmesi değerlendirilen 19 hastanın 8'inde $(\% 42,1)$ belli oranlarda iletim tipi işitme kaybı olduğu tespit edilmiştir.

Turner sendromlu erişkin kadınlarda, karaciğer enzim yükseklikleri ve nadir olarak siroz görülebilir. $\mathrm{Bu}$ bulguların patogenezi hala net değildir, farklı hastalarda farklı nedenlere bağlı olabilir. Bazı hastalarda steatoz veya nonalkolik yağlı karaciğer hastalığı, başka hastalarda otoimmün bir süreç karaciğer enzim yüksekliklerine neden olmuş olabilir. Transaminaz yükseklikleri genellikle rutin laboratuvar testlerinde saptanır ve çoğunlukla asemptomatiktir. Östrojen tedavisinin karaciğer enzim düzeylerinde düzelmeye yol açtığı gösterilmiștir ${ }^{30}$. Çalışmamızda iki asemptomatik olguda Alanin transaminaz yüksekliği tespit edildi ve her iki olguda da karaciğer enzim yüksekliklerine yol açan diğer nedenler ekarte edildi. $\mathrm{Bu}$ da TS'de izole karaciğer enzim yüksekliklerinin olabileceğini ve bu durumun akılda tutulması gerektiğini göstermektedir.

Çalışmamızın kısıtlı yönleri; planlamanın retrospektif yapılması, hasta dosyalarında TS'ye eşlik edebilen göz bulguları, iskelet problemleri, hipertansiyon varlığı ve kemik mineral yoğunluk ölçümü gibi verilerin eksik olması şeklinde sıralanabilir

Sonuç olarak; TS en sık boy kısalığı ve gecikmiş puberteye yol açar. Ek olarak konjenital kalp ve böbrek hastalıkları, gastrointestinal ve işitme problemleri, otoimmün hastalık sıklığında artış gibi birçok sistemi de etkilemektedir. Erken tanı konulması hem daha iyi boy kazancına hem de TS'ye eşlik eden patolojilerle ilgili komplikasyonların önlenmesine neden olacaktır. Bu çalışma, çocuklarda boy kısalığı ve hipergonadotropik hipogonadizm gibi kardinal bulguların olmamasının, TS tanısını ekarte etmeyeceğini göstermiştir.

Etik Kurul Onayı: Çalışma Dicle Üniversitesi Tıp Fakültesi Girişimsel Olmayan Klinik Araştırmalar Etik Kurulu onayı alındıktan sonra yapılmıştır (2020 / 323).

Çıkar Çatışması Beyanı: Yazarlar çıkar çatışması olmadığını bildirmişlerdir.

Finansal Destek: Bu çalışma herhangi bir fon tarafından desteklenmemiştir.

Declaration of Conflicting Interests: The authors declare that they have no conflict of interest.

Financial Disclosure: No financial support was received.

\section{KAYNAKLAR}

1. Saenger P, Wikland KA, Conway GS, et al., Recommendations for the Diagnosis and Management of Turner Syndrome1. The Journal of Clinical Endocrinology \& Metabolism, 2001; 86(7): 3061-69.

2. Nielsen $\mathrm{J}$ and Wohlert $\mathrm{M}$, Chromosome abnormalities found among 34910 newborn children: results from a 13-year incidence study in Århus, Denmark. Human Genetics, 1991; 87: 81-83.

3. Balkan M, Alp N, Yalınkaya A, et al. 46,X, i(Xq) Karyotipli Varyant Turner Sendromlu: Olgu Sunumu. Dicle Med J 2005; 32; 149-52. 
4. Turner HH. A syndrome of infantilism, congenital webbed neck and cubitus valgus. Endocrinol 1938; 23: 566-74.

5. Z Kinderheilk. Über typische Kombinationsbilder multipler Abartungen. Eur J Pediatr 1930; 49: 271.

6. Loscalzo ML, Turner Syndrome. Pediatrics in Review, 2008; 29: 219-27.

7. Gravholt CH, Andersen NH, Conway GS, et al., Clinical practice guidelines for the care of girls and women with Turner syndrome: proceedings from the 2016 Cincinnati International Turner Syndrome Meeting. European Journal of Endocrinology, 2017; 177: 1-70.

8. Neyzi O, Günöz H, Furman A, ve ark. Türk çocuklarında vücut ağırlığl, boy uzunluğu, baş çevresi ve vücut kitle indeksi referans değerleri. Çocuk Sağlığı ve Hastalıkları Dergisi. 2008; 51: 1-14.

9. Marshall WA, Tanner JM. Variations in pattern of pubertal changes in girls. Arch Dis Child. 1969;44: 291-303.

10. Backeljauw P. Clinical manifestations and diagnosis of Turner syndrome. In: Up To Date (online). Available at: www.uptodate.com/contents/clinicalmanifestations-and-diagnosis-of-turnersyndrome?. Accessed: October 21, 2020.

11. Sari E, Bereket A, Yeşilkaya E, et al. Anthropometric findings from birth to adulthood and their relation with karyotpye distribution in Turkish girls with Turner syndrome.

Am J Med Genet A. 2016 Apr;170A: 942-8. doi:10.1002/ajmg.a.37498. Epub 2016 Jan 20.

12. Brook CG, Mürset G, Zachmann M, Prader A. Growth in children with 45,XO Turner's syndrome. Arch Dis Child, 1974; 49: 789

13. Bereket A. Turan S, Ozkan B, et al. Adult height in Turkish patients with Turner syndrome without growth hormone treatment. Turk J Pediatr. 2008; 50: 415-7.

14. Saggese G, Federico G, Cinouanta L. Plasma growth hormone binding protein activity, insulinlike growth factor I, and Its binding protein levels in patients with Turner's syndrome:Effect of shortand kong-term recombinant human growth hormone administration. Pediatr Res, 1995: 37; 106-11

15. Hochberg Z, Avıram M, Rubın D, Pollack S. Decreased sensitivity to insulin-like growth factor I in Turner's syndrome: a study of monocytes and T lymphocytes. Eur J Clin Invest, 1997: 27; 543-7

16. Tanaka T, Igarashi Y, Ozono K, et al. Frequencies of spontaneous breast development and spontaneous menarche in Turner syndrome in Japan. Clinical Pediatric Endocrinology 2015; 24: 167-73. (doi:10.1297/cpe.24.167)

17. Negreiros LP, Bolina ER \& Guimaraes MM. Pubertal development profile in patients with Turner syndrome. Journal of Pediatric Endocrinology and Metabolism 2014: 27; 845-49.

18. Pasquino AM, Passeri F, Pucarelli I, Segni M \& Municchi G. Spontaneous pubertal development in Turner's syndrome. Italian Study Group for Turner's Syndrome. Journal of Clinical Endocrinology and Metabolism 1997: 82; 1810-3. (doi:10.1210/ jc.82.6.1810)

19. Mortensen $\mathrm{KH}$, Andersen $\mathrm{NH}$, Gravholt $\mathrm{CH}$. Cardiovascular phenotype in Turner syndrome-integrating cardiology, genetics, and endocrinology. Endocr Rev 2012; 33: 677.

20. Gotzsche CO, Krag-Olsen B, Nielsen J, KE Sørensen, BO Kristensenet. Prevalence of cardiovascular malformations and association with karyotypes in Turner's syndrome. Arch Dis Child 1994; 71: 433-36.

21. Baena N, De Vigan C, Cariati E, et al. Turner syndrome: evaluation of prenatal diagnosis in 19 European registries. Am J Med Genet A 2004; 129: 16-20.

22. Bondy CA, Turner Syndrome Study Group. Care of girls and women with Turner syndrome: a guideline of the Turner Syndrome Study Group. J Clin Endocrinol Metab 2007; 92: 10-25.

23. Bakalov VK, Gutin L, Cheng CM, et al. Autoimmune disorders in women with turner syndrome and women with karyotypically normal primary ovarian insufficiency. J Autoimmun 2012; 38: 315-321.

24. Elsheikh M, Wass JA, Conway GS. Autoimmune thyroid syndrome in women with Turner's 
syndrome--the association with karyotype. Clin Endocrinol (Oxf) 2001; 55: 223-26.

25. El-Mansoury M, Bryman I, Berntorp K, et al. Hypothyroidism is common in turner syndrome: results of a five-year follow-up. J Clin Endocrinol Metab 2005; 90: 2131-35.

26. Yeşilkaya E, Bereket A, Darendeliler F, et al. Turner syndrome and associated problems in Turkish children: a multicenter study. J Clin Res Pediatr Endocrinol. 2015 Mar; 7: 27-36. doi: 10.4274/jcrpe.1771.

27. Davenport ML, Roush J, Liu C, et al. Growth hormone treatment does not affect incidences of middle ear disease or hearing loss in infants and toddlers with Turner syndrome. Horm Res Paediatr 2010; 74: 23-32.
28. Barrenäs ML, Nylén O, Hanson C. The influence of karyotype on the auricle, otitis media and hearing in Turner syndrome. Hear Res 1999; 138: 163-70.

29. Jorge AA, Nishi MY, Funari MF, et al. [Short stature caused by SHOX gene haploinsufficiency: from diagnosis to treatment]. Arq Bras Endocrinol Metabol 2008; 52: 765-73.

30. Elsheikh M, Hodgson HJ, Wass JA, Conway GS. Hormone replacement therapy may improve hepatic function in women with Turner's syndrome. Clin Endocrinol (Oxf) 2001; 55: 227-31. 